\title{
Poor glycemic control can lead to an early appearance of atherosclerosis in patients with type 1 diabetes - Can this be avoided by effective educational programs?
}

${ }^{1}$ Faculdade de Medicina da Universidade Federal do Rio de Janeiro (UFRJ), Rio de Janeiro, RJ, Brasil

Correspondence to: Melanie Rodacki melanierodacki@gmail.com

Received on Nov/30/2017 Accepted on Nov/30/2017

DOI: 10.1590/2359-3997000000304
Melanie Rodacki ${ }^{1}$

$\mathrm{T}$ his issue of "Archives of Endocrinology and Metabolism" features two papers about type 1 diabetes mellitus (TIDM). Pacheco and cols. report the results of a structured education program for adults with TIDM from a single center in the south of Brazil. The education strategy consisted of workshops, individualized care and 24-hour distant support (1). The design of the program was inspired by the educational support provided in the Dose Adjustment for Normal Eating Study (DAFNE), performed in the UK (2). Fortunately, the authors report successful results, leading to a significant improvement in HbAlc (approximately $20 \%$ in one year with an additional reduction of $11 \%$ in the next 8 months) (1). Achieving the HbAlc goals in individuals with TIDM is still a major challenge worldwide. Although adults tend to have a slightly better glycemic control than younger patients, the proportion of individuals with 25 years of age or more who present $\mathrm{HbAlc}$ below $7.5 \%$ still varies between $20.5 \%$ and $53.6 \%$ in different countries, with a mean HbAlc between $8 \%$ and $8.5 \%$ in most populations that provide enough resources for diabetes care (3). A mean $\mathrm{HbAlc}$ of $9.2 \%$ has been previously reported for the Brazilian population, where the resources for diabetes care are limited and efficient national programs for diabetes care are still lacking (4).

Pacheco and cols. (1) reported a mean HbAlc of approximately $10.7 \%$ in males and $9.6 \%$ in females before the initiation of the educational program in one center in south Brazil. The authors achieved a mean HbAlc of approximately $8.5 \%$ for both men and women in the end of the study, which is still above the recommended goals for TIDM but at the same range obtained for countries that offer more resources for diabetes treatment and glucose monitoring than Brazil. A control group that did not participate in the educational program did not show any differences in the glycemic control in a similar time period, which reinforces the impact of the intervention in this study group. These results indicate that education can be an effective tool to obtain significant improvements in diabetes care in patients with TIDM, including poor countries with limited health-care resources.

Although the success of educational intervention programs had been reported in previous studies, including the DAFNE study itself $(2,5)$, this is not a rule. A meta-analysis failed to demonstrate strong benefits of educational programs in the improvement of glycemic control in patients with TIDM from different populations (6). As educational programs can vary significantly, the lack of success in achieving better glycemic control with such intervention might indicate the choice of an inadequate program or an erroneous selection of the intervention group. Therefore, successful models of educational programs for diabetes care, such as the one reported by Pacheco 
and DAFNE, should be replicated and further studied, in order to be included as part of the routine health care policies for patients with diabetes. This can represent a simple and cheap intervention to improve glycemic control in patients with TIDM worldwide, especially in poor countries.

Improving glycemic control in people with TIDM is particularly important as it is known that this can reduce the risk of diabetic chronic complications (7). The Diabetes Control and Complications Trial (DCCT)/Epidemiology of Diabetes Interventions and Complications (EDIC) Trial has shown that intensive insulin treatment aiming to achieve $\mathrm{HbAlc}$ $<7 \%$ has beneficial effects in the risk reduction not only of microvascular complications (8), but also of macrovascular complications (9). After the completion of the DCCT, which compared intensive therapy (IT) with a conventional therapy (CON) in the risk of chronic complications, patients were invited to take part of the EDIC Trial. This was an observational study where IT was offered to all participants that completed DCCT, independently of the previous group, due to the significant impact obtained with IT in the risk reduction of diabetic complications. Although the mean $\mathrm{HbAlc}$ significantly differed between the IT and CON groups during the DCCT, both groups had similar mean HbAlc levels during the EDIC trial. Nevertheless, the benefits of the intensive control observed during the DCCT not only persisted but also became more prominent during the EDIC, indicating the existence of a "metabolic memory" and showing the importance of maintaining a good glycemic control since the beginning of the disease (10).

Also in this issue of "Archives of Endocrinology and Metabolism", Tacito and cols. have shown that patients with TIDM had impaired endothelial function, when compared to healthy controls (11). The authors also compared the carotid artery intimamedia thickness (CIMT) between patients with TIDM and a control group using an automated system. Both endothelial dysfunction and CIMT are early markers of atherosclerosis, which are implicated in the pathogenesis of macrovascular complications. Even though both groups described in the study performed by Tacito and cols. had CIMT values within the normal range for age, patients with TIDM had higher CIMT than controls. Curiously, the study group was young, had a short disease duration (of approximately 4 years), normal body mass index (BMI), but had a high mean HbAlc (of 9.95\%) (11). It is possible that the poor glycemic control contributed to the precocious appearance of early atherosclerosis markers, even in this group of young lean patients with a short disease duration. This is consistent with the concept of "metabolic memory" and stresses the importance of starting an intensive treatment and achieving a good glycemic control since the beginning of the disease. Although endothelial function is closely related to TIDM duration, the early development of endothelial dysfunction in patients with TIDM, short disease duration and poor glycemic control had already been previously reported $(12,13)$. On the other hand, alterations in CIMT have been reported mostly in patients with longer disease duration (14-16). In the EDIC, after 1 year of follow-up, the carotid intimamedia thickness in patients with TIDM with a mean disease duration of approximately 14 years was similar to that in an age- and sex-matched nondiabetic population, both in CON and IT groups (17).

Another possible explanation for the findings seen in the study performed by Tacito and cols. (11) is the difference in TSH levels between the groups (patients vs controls). Several studies have reported a link between CIMT and subclinical hypothyroidism (18-20), but Takamura and cols. have also reported an association between TSH and CIMT in euthyroid individuals (21). Although TSH levels were within the normal range in both groups, the levels significantly differed between them. Indeed, it has been suggested that a narrower thyrotropin reference range should be used in the general population (22) as the current reference ranges have been defined in populations previously considered healthy but included individuals with various degrees of thyroid dysfunction. Moreover, we have previously found that TSH levels $>2.5 \mathrm{mU} / \mathrm{l}$, even in the normal range, are associated with a higher risk of retinopathy and renal dysfunction in patients with TIDM than TSH levels between 0.4 and $2.5 \mathrm{mU} / \mathrm{l}$ (23). Possibly, the same association could be observed for macrovascular complications. This would be an alternative explanation for the finding obtained by Tacito and cols. (11) and worth further investigation, since thyroid diseases are more frequent in patients with TIDM than in the general population.

To conclude, the two interesting papers featured in this issue of "Archives of Endocrinology and Metabolism" bring us very important messages. Firstly, patients with TIDM and poor glycemic control might develop early signs of atherosclerosis even in the first 
few years of the disease, at a young age and with normal BMI. Secondly, efficient educational programs can lead to a significant reduction of $\mathrm{HbAl}$ c levels in patients with TIDM, which can lead to a significant risk reduction of micro and macrovascular diabetic complications. Therefore, effective educational programs should be implemented soon after the diagnosis of TIDM, in order to avoid poor glycemic, metabolic memory and their possible adverse effects.

Disclosure: no potential conflict of interest relevant to this article was reported.

\section{REFERENCES}

1. Pacheco APF, Sande-Lee SV, Sandoval RCB, Batista S, Marques JLB. Effects of a structured education program on glycemic control in type 1 diabetes. Arch Endocrinol Metab. 2017;61(6):534-41.

2. Kruger J, Brennan A, Thokala P, Basarir H, Jacques R, Elliott J, et al. The cost-effectiveness of the Dose Adjustment for Normal Eating (DAFNE) structured education programme: an update using the Sheffield Type 1 Diabetes Policy Model. Diabet Med. 2013;30(10):1236-44.

3. McKnight JA, Wild SH, Lamb MJ, Cooper MN, Jones TW, Davis EA, et al. Glycaemic control of Type 1 diabetes in clinical practice early in the 21st century: an international comparison. Diabet Med. 2015;32(8):1036-50.

4. Gomes MB, Cobas RA, Matheus AS, Tannus LR, Negrato CA, Rodacki $M$, et al. Regional differences in clinical care among patients with type 1 diabetes in Brazil: Brazilian Type 1 Diabetes Study Group. Diabetol Metab Syndr. 2012;4(1):44.

5. Cooke D, Bond R, Lawton J, Rankin D, Heller S, Clark M, et al.; U.K. NIHR DAFNE Study Group. Structured type 1 diabetes education delivered within routine care: impact on glycemic control and diabetes-specific quality of life. Diabetes Care. 2013;36(2):270-2.

6. Pillay J, Armstrong MJ, Butalia S, Donovan LE, Sigal RJ, Chordiya P, et al. Behavioral Programs forType 1 Diabetes Mellitus: A Systematic Review and Meta-analysis. Ann Intern Med. 2015;163(11):836-47.

7. Fullerton B, Jeitler K, Seitz M, Horvath K, Berghold A, Siebenhofer A. Intensive glucose control versus conventional glucose control for type 1 diabetes mellitus. Cochrane Database Syst Rev. 2014;(2):CD009122.

8. Diabetes Control and Complications Trial Research Group, Nathan DM, Genuth S, Lachin J, Cleary P, Crofford O, Davis M, et al. The effect of intensive treatment of diabetes on the development and progression of long-term complications in insulin-dependent diabetes mellitus. N Engl J Med. 1993;329(14):977-86.

9. Nathan DM, Cleary PA, Backlund JY, Genuth SM, Lachin JM, Orchard TJ, et al.; Diabetes Control and Complications Trial/ Epidemiology of Diabetes Interventions and Complications (DCCT/EDIC) Study Research Group. Intensive diabetes treatment and cardiovascular disease in patients with type 1 diabetes. $\mathrm{N}$ Engl J Med. 2005;353(25):2643-53.
10. Zhang L, Chen B, Tang L. Metabolic memory: mechanisms and implications for diabetic retinopathy. Diabetes Res Clin Pract. 2012;96(3):286-93.

11. Tacito LHB, Pires AC, Yugar-Toledo JC. Impaired flow-mediated dilation response and carotid intima-media thickness in patients with type 1 diabetes mellitus with a mean disease duration of 4.1 years. Arch Endocrinol Metab. 2017;61(6):542-9.

12. Mahmud FH, Earing MG, Lee RA, Lteif AN, Driscoll DJ, Lerman A. Altered endothelial function in asymptomatic male adolescents with type 1 diabetes. Congenit Heart Dis. 2006;1(3):98-103.

13. Bertoluci MC, Cé GV, da Silva AM, Wainstein MV, BoffW, Puñales M. Endothelial dysfunction as a predictor of cardiovascular disease in type 1 diabetes. World J Diabetes. 2015;6(5):679-92.

14. Kupfer R, Larrúbia MR, Bussade I, Pereira JRD, Lima GAB, Epifanio MA, et al. Predictors of subclinical atherosclerosis evaluated by carotid intima-media thickness in asymptomatic young women with type 1 diabetes mellitus. Arch Endocrinol Metab. 2017;61(2):115-21.

15. Shah AS, Dabelea D, Fino NF, Dolan LM, Wadwa RP, D'Agostino R $\mathrm{Jr}$, et al. Predictors of Increased Carotid Intima-Media Thickness in Youth With Type 1 Diabetes:The SEARCH CVD Study. Diabetes Care. 2016;39(3):418-25.

16. Sun YP, Cai YY, Li HM, Deng SM, Leng RX, Pan HF. Increased carotid intima-media thickness (CIMT) levels in patients with type 1 diabetes mellitus (T1DM): A meta-analysis. J Diabetes Complications. 2015;29(5):724-30.

17. Nathan DM, Lachin J, Cleary P, OrchardT, Brillon DJ, Backlund JY, et al.; Diabetes Control and Complications Trial; Epidemiology of Diabetes Interventions and Complications Research Group. Intensive diabetes therapy and carotid intima-media thickness in type 1 diabetes mellitus. N Engl J Med. 2003;348(23):2294-303.

18. Peixoto de Miranda ÉJ, Bittencourt MS, Pereira AC, Goulart AC, Santos IS, Lotufo PA, et al. Subclinical hypothyroidism is associated with higher carotid intima-media thickness in cross-sectional analysis of the Brazilian Longitudinal Study of Adult Health (ELSA-Brasil). Nutr Metab Cardiovasc Dis. 2016;26(10):915-21.

19. Unal E, Akın A,Yıldırım R, DemirV,Yildiz I, HaspolatYK. Association of Subclinical Hypothyroidism with Dyslipidemia and Increased Carotid Intima-Media Thickness in Children. J Clin Res Pediatr Endocrinol. 2017;9(2):144-9.

20. Gao N, Zhang W, Zhang YZ, Yang Q, Chen SH. Carotid intimamedia thickness in patients with subclinical hypothyroidism: a meta-analysis. Atherosclerosis. 2013;227(1):18-25.

21. Takamura N, Akilzhanova A, Hayashida N, Kadota K, Yamasaki $H$, Usa $T$, et al. Thyroid function is associated with carotid intima-media thickness in euthyroid subjects. Atherosclerosis. 2009;204(2):e77-81.

22. Baloch Z, Carayon P, Conte-Devoix B, Demers LM, FeldtRasmussen $\mathrm{U}$, Henry JF, et al. Laboratory medicine practice guidelines. Laboratory support for the diagnosis and monitoring of thyroid disease. Thyroid. 2003;13:3-126.

23. Rodacki M, Zajdenverg L, Dantas JR, de Oliveira JE, Luiz RR, Cobas RA, et al. Should thyroid-stimulating hormone goals be reviewed in patients with type 1 diabetes mellitus? Results from the Brazilian Type 1 Diabetes Study Group. Diabet Med. 2014;31(12):1665-72. 